\title{
Preparation of Engineered Carbon Nanorods from Garbage Leachate by Pyrolysis on the Sand Particles and Its Application for 4- Nonylphenol Removal from Surface Water
}

\author{
${ }^{1-}$ Mastaneh Safari, ${ }^{2-I m a n ~ M o s a d d e g h ~}$ \\ 1- Ph.D. in environmental engineering, Graduate Faculty of Environment, University of Tehran, Iran \\ 4- B.Sc. in civil engineering, Azad University of Mashhad, Mashhad, Iran
}

\begin{abstract}
A B S T R A C T
Silica sand filters are usually employed for water treatment. Their capacity for removal of 4nonylphenol from the water streams is low. In addition, for using nano-adsorbents in the slurry mode, they should be removed at the end of the process. These problems in this study were solved by the immobilization of nanorods on silica particles. The acid-washed sand particles were mixed constantly with the garbage leachate on a heater so that they were covered completely with the garbage leachate. Then, the obtained particles were put in the furnace and pyrolyze (at varying temperatures in a range of 300 to $800{ }^{\circ} \mathrm{C}$ ) for preparation of the nanocomposite. According to the scans from scanning electron microscopy and results of the Raman test, the nanotubes were formed on the silica surface. Furthermore, the EDS analysis results for carbon nanorods showed the existence of oxygen, silica, and a small amount of aluminium. The 4Nonylphenol adsorption was examined using a new nanocomposite under various operating circumstances (initial concentration, contact time, temperature). The isotherm, kinetics, and thermodynamics of the adsorption process were also studied. Following a different regeneration process, data indicated that the novel developed material is an appropriate recyclable adsorbent that can be used in water treatment.
\end{abstract}

Keywords: Nanorods; Removal; Sand particles; Water treatment; 4-Nonylphenol; Garbage leachate 


\section{Introduction}

According to the UN, almost four billion people are living in areas with water scarcity, and it is expected to reach six billion by 2050 [1]. In the late 2000s, studies on emerging pollutants started, and the research findings indicated that these pollutants exist in soil, sediments, and air, as well as sewage, water, and aquatic environments [2], [3], [4]. As these materials have low toxicity at very low concentrations and can cause disease, they are known as micropollutants (MPs) [5]. Also, projections of climate change modelling efforts indicate that the changing climate will impact each component of the climate system with regional differences and this will change patterns of climate variables such as temperature and precipitation which consequently will affect water resources [6], [7], [8], [9], [10]. Water contamination by emerging pollutants is a crucial environmental problem [11], [12], [13], [14]. These compounds create problems both in domestic wastewater and industrial wastewater [15]. Water and wastewater treatment plants often lack a process for removal of these pollutants [16]. Some of these MPs, like 4Nonylphenol(4-NP), Bisphenol A(BPA), and 4-Octylphenol(4-OP), have been identified as endocrine disrupters as they influence the endocrine system and recently have drawn considerable attention [17]. It is regarded as a critical hazard to the reproductive system and the organism's growth ability [18]. Nonylphenol (NPs) can penetrate the human body via polluted foods and water. OP and NP exist in plastic containers as well as containers that can enter drinking water or food. In addition, they can also enter the human body via detergents and personal care goods and through spermicides in contraception. It is possible to detect the NP presence in the human body by human blood, urine, and milk [2]. As reported by the US EPA, the NP risks have been confirmed and the recommended concentration for freshwater is below 6.6 $\mathrm{mgL}^{-1}[19]$. Thus, proposing sensitive and effective identification approaches for monitoring 4OP, 4-NP, and BPA in water samples is urgent [17]. The new solutions should be found for eliminating MPs - both from water and real wastewaters. These solutions should have chemical efficiency, technical feasibility, and economic viability, and be environment-friendly. For this purpose, biologists, chemists, engineers, polymerizers, and microbiologists should adopt a multidisciplinary approach to work cooperatively toward a shared goal [2]. During the last decades, researchers have proposed different approaches, like oxidation, biological treatment, 
adsorption, etc. for the elimination of the NP [20]. Despite their high efficiency, these techniques are seldom utilized in water treatment plants. Its reason could be high operational costs, or probably due to the production of toxic products, like oxidation processes, because of their nondiffusion at the surface scale [21]. Various therapeutic processes can be used for achieving 4-NP, including biotechnological-based techniques (immobilized enzymes, biofilms, etc.), biological (membrane bioreactors) or physical procedures (membrane filtration, e.g., nanofiltration), or use of absorption-oriented processes. The adsorption process was eliminated from the drinking water. Conventional adsorbents (activated carbon) or non-conventional adsorbents (cyclodextrin, clay, etc.), and oxidation processes (photo catalysis, sonochemistry, and photolysis) [22].

Tro et al. in their study, eliminated NP from municipal wastewater using the constructed wetland. Their experimental findings indicated that $60-73 \%$ removal percentage was achieved [23]. Cheng et al. removed phenol by acid-washed zero-valent aluminium. Their experimental results showed that the phenol amount was reduced from 0.3 to $20 \mathrm{mg} \mathrm{L}^{-1}$ [23]. Asmaly et al. investigated phenol removal by oxidized nanoparticles. According to their findings, the tested nanoparticles had the capability of removal of phenol [24]. The recent progresses in technologies have led to generation of other carbon structures, like Nano absorbent [25]. Nano absorbent with mesoporous structures has shown excellent potential in NP adsorption. It previously has been used for removal of organic matters, like pharmaceuticals, organic dyes, pesticides, natural organic material (NOM), and aromatic amines [26]. Despite high potential of nano absorbent in removal of $\mathrm{MP}$, it is problematic to use them in the slurry state since they need to eliminated removed in the final treatment. In addition, silica sand is a very good natural source to be utilized in filters of water treatment plants. Despite proved efficacy of rapid sand filters in removal of some pollutants, they fail to eliminate 4-NP. When silica sand is coated with nano absorbent, the problems at slurry state is solved and silica grain capability is enhanced, resulting in generation of novel adsorbent NRs. Though there is a long way for this technology to be practically used, it might be an efficient phase in the enhancement of silica grain [27]. For 4-NP determination, different analytic approaches have been presented. These approaches include Gas chromatography with mass spectrometry, liquid-chromatography, liquid-chromatography 
electrospray ionization mass spectrometry, etc. [18]. Collection and disposal of urban wastes are one of the major points in integrated management of municipal waste because of industrialization, population growth, and subsequently, increasing waste production per capita [28]. Garbage leachate composes a complicated matrix of different chemicals, including inorganic salts, dissolved organic matter, heavy metals, and organic trace impurities. Each of these chemicals has different concentrations because of the chemical, physical, and microbiological procedures that happen in the deposited waste [29]. The garbage leachate composition is affected by many factors, including deposited waste type, the way of landfill exploitation, and the oxygen availability, as well as the landfill age and hydrogeological conditions [30]-[32]. This issue has resulted in increased environmental and health hazards [8].

Nanorods immobilized on the silica surface were generated in the present study by the pyrolysis of garbage leachate on the sand particles. We dried the garbage leachate on the surface of acid-washed sand particles. Then, the pyrolysis was performed at varying temperatures. EDAX, FESEM, and ramen analysis were conducted for characterization of the nanocomposite. Afterward, the developed adsorbent's performance was evaluated in terms of the 4-NP removal using the experiments at varying concentrations. Moreover, isotherm, kinetics, and thermodynamic adsorption tests were conducted. In the end, the desorption and adsorption rate of the adsorbents were examined for up to seven cycles.

\section{Materials and methods}

\subsection{Chemicals}

4-NP, Nitric acid ( $\mathrm{HNO}_{3}$ Synth \%65, hydrochloric acid, Synth\% 37), Ethanol and Methanol, $\mathrm{KNO}_{3}$, Dichloromethane, $\mathrm{KH}_{2} \mathrm{PO}_{4}, \mathrm{MgSO}_{4}$, Acetonitrile, $\mathrm{NaHCO}_{3}$, and $\mathrm{CaCl}_{2}$ were prepared by Merck German dealers. Silica grains gifted by TSoil Mechanics Laboratory, Faculty of Engineering, University of Tehran. Based on the information provided by the manufacturer, these grains have \%97.5 $\mathrm{SiO}_{2}$ plus other impurities, like $\mathrm{MgO}, \mathrm{Fe}_{2} \mathrm{O}_{3}, \mathrm{Al}_{2} \mathrm{O}_{3}, \mathrm{~K}_{2} \mathrm{O}$, and $\mathrm{CaO}$. Garbage leachate from Aradkoh Waste Processing and Recycling Complex of Kahrizak (located $23 \mathrm{~km}$ away from the old 
Tehran-Qom Highway and south of Kahrizak). We prepared a stock solution (1000 mg L-14-NP) by dissolving 4-NP in deionized water.

\subsection{Instruments}

In order to examine stability of NRs immobilized on the surface of silica particles, an ultrasound bath (HWASHIN, Seoul, Korea) was used.

\subsection{Preparation of Adsorbent}

For the preparation of NRs, the acid-washed sand particles were mixed constantly with the garbage leachate on a heater until the dried garbage leachate completely covered the sand particles. Then, the obtained particles were placed in the furnace and pyrolyze for preparation of the nanocomposite. Hence, firstly, $500 \mathrm{~mL}$ of diluted hydrochloric acid $37 \%$ with water in a $1: 1$ ratio was added to $500 \mathrm{gr}$ of silica sand. Next, the $100{ }^{\circ} \mathrm{C}$ temperature was applied for heating the resulting mixture for three hours. Later, it was rinsed with deionized water, and it was dried under a lab oven for 24 hours. Then, $500 \mathrm{~mL}$ of the garbage leachate was mixed with the acidwashed sand and heated and concurrently stirred consciously so that the garbage leachate is completely coated on the sand. In the next step, the garbage leachate-coated sand was placed in the furnace, and it was programmed to reach $700^{\circ} \mathrm{C}$ at 15 minutes. Next, it was stored at $700^{\circ}$ C for one hour. The generated nanocomposite was rinsed several times with distilled water for washing the additional salts from the surface of the sand particles. However, it should be mentioned that the temperature can be a factor affecting the formation of NRs. Thus, the pyrolysis temperature was done at varying temperatures with a range of 300 to $800^{\circ} \mathrm{C}$. 


\subsection{Characterization of NRs}

For determination of chemical and physical characteristics of prepared NRs, SEM, EDS, and Raman spectroscopy were employed. SENTERRA 2009 (BRUKER, Germany) was used for Raman spectroscopic analysis. Field emission scanning electron microscopy was utilized to observe details of topography and structures of raw sand, NRs, and acid-washed sand. The EDS test was conducted using FESEM TESCAN with the French-made MIRA III SAMX detector.

\subsection{Determination of 4-NP}

HPLC (Agilent 1100) was used for the determination of the residual concentration of 4-NP, which was equipped with a UV detector and a C18 column ( $5 \mu \mathrm{m}, 4.6 \times 250 \mathrm{~mm})$, used in isocratic elution mode. A constant composition of the mobile phase was observed in the isocratic mode. We used Acetonitrile: water (80:20) as the mobile phase with a $1 \mathrm{ml} \mathrm{min}^{-1}$ flow rate. Prior to injecting samples into the column, PTEF syringe filters $(0.2 \mu \mathrm{m})$ were used for filtering them.

\subsection{Batch adsorption experiments}

For optimizing a process and predicting the experimental results in the past, many experiments were required to be conducted. During the experiments, one factor had a variable value, while the others have constant values. This optimization approach was called oneparameter-at-a-time. Its main disadvantages are the requirements of a high number of experiments, and the conducting of experiments is costly and time-consuming. Besides, this approach failed to include the interaction between parameters. Some multivariate static methods were presented for overcoming these shortcomings. One of the famous techniques is the response surface methodology (RSM), which constitutes various statistical models, among which central composite design (CCD) is among the most effective ones [33].

Design Expert 10 Software (Stat-Ease Inc.) was employed for optimization of the CCD-based adsorption process to gain the minimum equilibrium concentration of adsorbate as the response 
that is a function of adsorbent loading, initial concentration, and contact time. The value ranges were allocated to effective parameters on the basis of the pre-tests. Real values were delivered into the dimensionless values using the relation below to be able to compare different factors with different units [34].

$$
\mathrm{Z}_{\mathrm{i}}=\frac{\mathrm{x}_{\mathrm{i}}-\mathrm{x}_{0}}{\Delta \mathrm{x}}
$$

Where $Z_{i}$ denotes a variable's dimensionless value, $X i$ indicates the variable's real value, $\Delta X$ indicates step change, Xo represents a variable's real value at the centre point. The amount of $\alpha$ is associated with the number of variables, and it can be obtained using the relation below:

$$
\alpha=2^{(k / 4)}
$$

Where $\mathrm{k}$ indicates the number of variables. When the ranges of variables were entered in the software, we designed 19 experiments ( 5 central points, 8-factor points, and 6 axial points) according to CCD for 4-NP adsorption (Table 1). The number of runs was given by:

$$
\mathrm{N}=\mathrm{k}^{2}+2 \mathrm{k}+\mathrm{c}_{\mathrm{p}}
$$

Where $c_{p}$ represents the replicate number of the central point, and $k$ represents the number of independent variables. The software developed the quadratic equation for regression analysis, and the predicted response was presented as below:

$$
y=\beta_{0}+\sum_{i=1}^{k} \beta_{i} x_{i}+\sum_{i=1}^{k} \beta_{i i} x_{i}^{2}+\sum_{1 \leq i \leq j}^{k} \beta_{i j} x_{i} x_{j}+\varepsilon
$$

Where $x_{i}$ is independent variables, $y$ represents the response value, $\beta_{0}$ denotes the constant term, and $\varepsilon$ represents the error, and $\beta_{i}, \beta_{i i}$, and $\beta_{i j}$ denote coefficients of linear, squared, and interaction effects [35]. A certain amount of NRs (0.1-5 gr) in all experiments was added to 100 $\mathrm{mL}$ of a solution having 4-NP (0.1-2.0 $\left.\mathrm{mg} \mathrm{L}^{-1}\right)$. A mechanical stirrer was utilizing for mixing (100$120 \mathrm{rpm}$ ). All the tests related to the isotherm, kinetics, and thermodynamic were run 3 times and the mean values were expressed. In these experiments, the maximum variance coefficient was below $10 \%$. 
Table 1. Design matrix experiments

\begin{tabular}{|c|c|c|c|c|c|}
\hline Run & $\begin{array}{l}\text { A:4-NP } \\
m g L^{-1}\end{array}$ & $\begin{array}{l}\text { B: Time } \\
\text { min }\end{array}$ & $\begin{array}{c}\text { C: adsorbent } \\
\mathrm{g} \mathrm{L}^{-1}\end{array}$ & $\begin{array}{c}\text { Removal } \\
\text { (\%) }\end{array}$ & $\begin{array}{c}\mathrm{Ce} \\
\left(\mathrm{mg} \mathrm{L}^{-1}\right)\end{array}$ \\
\hline 1 & 1.0 & 21 & 25.5 & 71.10 & 0.29 \\
\hline 2 & 2.0 & 2 & 1.0 & 25.16 & 1.50 \\
\hline 3 & 1.0 & 40 & 25.5 & 82.11 & 0.18 \\
\hline 4 & 1.0 & 2 & 25.5 & 47.32 & 0.53 \\
\hline 5 & 0.1 & 2 & 50.0 & 77.88 & 0.02 \\
\hline 6 & 0.1 & 40 & 1.0 & 58.32 & 0.04 \\
\hline 7 & 0.1 & 21 & 25.5 & 77.69 & 0.02 \\
\hline 8 & 2.0 & 40 & 50.0 & 93.78 & 0.12 \\
\hline 9 & 1.0 & 21 & 25.5 & 68.20 & 0.32 \\
\hline 10 & 2.0 & 40 & 1.0 & 65.31 & 0.69 \\
\hline 11 & 1.0 & 21 & 1.0 & 52.31 & 0.48 \\
\hline 12 & 2.0 & 2 & 50.0 & 54.37 & 0.91 \\
\hline 13 & 1.0 & 21 & 25.5 & 69.40 & 0.31 \\
\hline 14 & 1.0 & 21 & 25.5 & 71.21 & 0.29 \\
\hline 15 & 1.0 & 21 & 50.0 & 87.45 & 0.13 \\
\hline 16 & 2.0 & 21 & 25.5 & 62.11 & 0.76 \\
\hline 17 & 1.0 & 21 & 25.5 & 70.81 & 0.29 \\
\hline 18 & 0.1 & 2 & 1.0 & 37.16 & 0.06 \\
\hline 19 & 0.1 & 40 & 50.0 & 96.87 & 0.00 \\
\hline
\end{tabular}

\subsection{Adsorption isotherms}

Isotherm models generally represent the adsorbate distribution between a solid phase at a constant temperature and the aqueous solution [36]. Five isotherm models (Freundlich, Langmuir, Radke- Prausnitz, Redlich-Peterson, Dubinin- Radushkevich, and UT (University of Tehran) were utilized for finding the best data fitting for representing the adsorption behavior. Langmuir is one of the most prevalent isotherm models, in which it is presumed that mono-layer adsorption occurs on the homogenous adsorbent surface, and the adsorption process stops after saturation [37]. The following equation represents Langmuir model: 


$$
\frac{C_{e}}{q_{e}}=\frac{1}{K_{L} q_{m}}+\frac{C_{e}}{q_{m}}
$$

Where $\mathrm{q}_{\mathrm{m}}$ denotes the maximum adsorption capacity $\left(\mathrm{mg} \mathrm{g}^{-1}\right)$, $\mathrm{q}_{\mathrm{e}}$ denotes the adsorbed amount on the solid phase under the equilibrium $\left(\mathrm{mg} \mathrm{g}^{-1}\right), \mathrm{KL}_{\mathrm{L}}$ denotes the equilibrium Langmuir constant $\left(\mathrm{mg} \mathrm{L}^{-1}\right)$, and $\mathrm{C}_{\mathrm{e}}$ indicates the equilibrium concentration $\left(\mathrm{mg} \mathrm{L}^{-1}\right)$.

Some adsorption features can be inferred by calculating $\mathrm{R}_{\mathrm{L}}$, as a dimensionless factor:

$$
R_{l}=\frac{1}{1+b C_{0}}
$$

Various amount of $R_{L}\left(R_{L}>1,0<R_{L}<1, R_{L}=1\right.$, and $\left.R_{L}=0\right)$ suggest unfavourable, good, linear, and irreversible adsorption [38].

Freundlich isotherm presents a multilayer non-ideal adsorption on heterogeneous surfaces [30]. It is given by the equation:

$$
\ln q_{e}=\ln K_{F}+\frac{1}{n_{F}} \ln C_{e}
$$

Where $\mathrm{n}_{\mathrm{f}}$ and $\mathrm{K}_{\mathrm{F}}\left(\mathrm{mg} \mathrm{g}^{-1}(\mathrm{~L} \mathrm{mg})^{1 / \mathrm{n}}\right)$ are Freundlich constants.

UT isotherm model [39] is independent of dose, and it has the capability of estimating the maximum adsorption capacity. The adsorption capacity that is given by the UT model is associated with multi-layer adsorption, whilst the adsorption capacity achieved by the Langmuir model is related to the monolayer adsorption on the adsorbent surface.

Radushkevich (1965) and Dubinin (1945) presented an isotherm that corresponds to the porous structure of the adsorbent. The relation is expressed as follows:

$$
\ln q_{e}=\ln q_{s}-\beta \varepsilon^{2}
$$

Where $q_{s}$ represents theoretical saturation capacity $\left(\mathrm{mg} \mathrm{g}^{-1}\right), \beta$ represents the DubininRadushkevich surface adsorption constant $\left(\mathrm{mol}^{2} \mathrm{~J}^{2}\right)$, and $\varepsilon$ represents Dubinin-Radushkevich constant. $\beta$ corresponds to the free mean energy that is the adsorption energy of one mole of adsorbate as it is adsorbed to the solid phase. It is given as below [40, 41]:

$$
E=\frac{1}{\sqrt{2 \beta}}
$$


Where E corresponds to free energy $\left(\mathrm{kJ} \mathrm{mol}^{-1}\right)$. Polanyi potential $\varepsilon$ can be written as follows [42]:

$\varepsilon=R T \operatorname{Ln}\left(1+\frac{1}{C_{0}}\right)$

Where $\mathrm{T}$ represents the absolute temperature $(\mathrm{K})$ and $\mathrm{R}\left(8.314 \mathrm{~J} \mathrm{~mol}^{-1} \mathrm{~K}^{-1}\right)$ denotes the universal gas constant.

Redlich-Peterson model is composed of the properties of Freundlich and Langmuir isotherms and can be expressed by the equation below [42]:

$$
\ln \left(K_{R} \frac{C_{e}}{q_{e}}-1\right)=g \ln C_{e}-\ln \alpha_{R}
$$

Where $C_{e}$ indicates the equilibrium concentration of adsorbate $\left(\mathrm{mg} \mathrm{L}^{-1}\right), \alpha\left(\mathrm{L} \mathrm{mg}^{-1}\right)$ and $\mathrm{K}_{\mathrm{R}}\left(\mathrm{Lg}^{-}\right.$ $\left.{ }^{1}\right)$ are Redlich-Peterson constants, and g denotes the Redlich-Peterson exponent. RedlichPeterson combines Freundlich and Langmuir models and features both of these models. RedlichPeterson is approached to the Freundlich model at high concentration, and it approaches the Langmuir model at low concentration.

\subsection{Adsorption kinetics}

The kinetic analysis can be helpful for realizing the adsorption mechanism. In the present research, five kinetic models, including Pseudo-second order, Pseudo-first order, liquid film diffusion, Intraparticle diffusion, and Elovich were used.

The pseudo-first-order is a straightforward kinetic model for the reversible reaction between a liquid and a solid phase. It can be expressed mathematically as below:

$$
\log \left(q_{e}-q_{t}\right)=\log \left(q_{e}\right)-\frac{k_{1} t}{2.303}
$$

Where $\mathrm{K} 1$ denotes pseudo-first-order constant $\left(\mathrm{min}^{-1}\right)$, and qe and qt represent the amounts of adsorbed material $\left(\mathrm{mg} \mathrm{g}^{-1}\right)$ at the equilibrium and at the time $\mathrm{t}$.

All adsorption steps are included in the pseudo-second-order model: adsorption, external film penetration, internal distribution, and it can be written as follows [42] : 


$$
\frac{t}{q_{t}}=\frac{1}{k_{2} q_{e}^{2}}+\left(\frac{1}{q_{e}}\right) t
$$

Where $\mathrm{K}_{2}$ represents pseudo-second-order constant $\left(\mathrm{g} \mathrm{mg}^{-1} \mathrm{~min}^{-1}\right)$.

Elovich is one of the commonly used kinetic models, which is based on adsorbing adsorbate without desorption, and the adsorbate thickness on the surface of the adsorbent increases over time. Therefore, the adsorption rate reduces $[39,43]$. The Elovich is expressed as:

$$
q_{t}=\frac{1}{\beta} \ln (\alpha \beta)+\frac{1}{\beta} \ln (t)
$$

Where $\alpha$ represents $\beta$ indicates Elovich constant $\left(\mathrm{g} \mathrm{mg}^{-1}\right.$ ) and initial adsorption rate ( $\mathrm{mg} \mathrm{g}^{-1}$ $\mathrm{min}^{-1}$ ). Exploring Intraparticle diffusion. Transport process during the adsorption of 4-NP on the adsorbent, Intraparticle diffusion model was employed. The model can be expressed as follows [44].

$$
\mathrm{q}_{\mathrm{t}}=\mathrm{k}_{p} \mathrm{t}^{1 / 2}+\mathrm{C}
$$

Where $C$ represents the intercept and $k_{p}$ indicates Intraparticle diffusion rate constant $\left.\left(\mathrm{mg} \mathrm{g}^{-1} \min ^{-1 / 2}\right)\right)$.

The following equation expresses the liquid film diffusion model [45]:

$$
\operatorname{Ln}(1-\mathrm{F})=-\mathrm{k}_{\mathrm{fd}} \mathrm{t}
$$

Where $F$ represents the fractional attainment of equilibrium at time $\mathrm{t}\left(F=\frac{q_{t}}{q_{e}}\right)$ and $\mathrm{k}_{\mathrm{fd}}$ denotes liquid film diffusion constant $\left(\mathrm{min}^{-1}\right)$.

\subsection{Adsorption thermodynamic}

Thermodynamic parameters need to be determined for investigation of the thermodynamic behaviors of 4-NP on NRs. The following equations were used for estimating thermodynamic parameters: standard entropy change $\Delta \mathrm{S}^{\circ}\left(\mathrm{J} \mathrm{mol}^{-1} \mathrm{~K}^{-1}\right)$, standard enthalpy change $\Delta \mathrm{H}^{\circ}\left(\mathrm{kJ} \mathrm{mol}^{-1}\right)$, and Gibbs free energy change $\Delta \mathrm{G}^{\circ}\left(\mathrm{kJ} \mathrm{mol}^{-1}\right)[46]$, where $\mathrm{R}$ indicates gas constant $\left(8.314 \mathrm{~J} \mathrm{~mol}^{-1} \mathrm{~K}^{-}\right.$ 
$\left.{ }^{1}\right)$, $T$ denotes absolute temperature, and $k_{c}$ denotes thermodynamic equilibrium constant of adsorption. The $\Delta \mathrm{S}^{\circ}$ and $\Delta \mathrm{H}^{\circ}$ values are measured from the plot intercept and slope in $\mathrm{K}_{\mathrm{c}}$ against 1.T. The negative $\Delta G^{\circ}$ values in all temperatures proved the adsorption as a spontaneous and feasible process. In addition, the $\Delta G^{\circ}$ spontaneous by increasing the temperatures suggest that high temperatures provide better states for absorption. That is, high temperatures are optimal and favorable [47]. The positive $\Delta \mathrm{H}^{\circ}$ value implies that the endothermic nature of the adsorption. The positive value of $\Delta S^{\circ}$ implies increasing randomness degree at the solid-liquid interface [48]:

$$
\begin{gathered}
\ln K_{c}=\frac{\Delta S^{\circ}}{R}-\frac{\Delta H^{\circ}}{R T} \\
\Delta G^{\circ}=\Delta H^{\circ}-T \Delta S^{\circ}
\end{gathered}
$$

\subsection{New adsorbent regeneration}

Regeneration as a critical parameter determines whether adsorbent is cost-effective or not [43]. Because of the expensiveness of Nano absorbent, the desorption of pollutants from absorbent surface is a crucial phase. For regeneration of the adsorbent, we added $2 \mathrm{mg} \mathrm{L}^{-1}$ of 4$\mathrm{NP}$ and $5 \mathrm{gr}$ of adsorbent to $100 \mathrm{~mL}$ of distilled water, and it was stirred for 21 minutes using a magnetic stirrer. HPLC determined the residue of 4-NP in solution. Next, the adsorbent was rinsed with methanol for removal of the adsorbates from the adsorbent surface, and it was reused.

\section{Results and discussions}

\subsection{Manufactured NRs}


The adsorbent pyrolysis was performed at $300-800{ }^{\circ} \mathrm{C}$. SEM results and absorption experiments showed the optimal temperature at $700{ }^{\circ} \mathrm{C}$. Thus, the NRs generated at $700{ }^{\circ} \mathrm{C}$ were utilized.

\subsection{Characterization}

SEM was utilized for morphological detection in raw sand and its possible alterations in acid sand, sand-covered with waste garbage leachate and sand-covered by carbon nanoparticles. Based on the SEM images (Fig.1. e and $\mathbf{f}$ ), there is not any specific phenomenon in the raw sand and acid wash. However, short nanotubes are observed in the sand coated with carbon nanoparticles, and a critical alteration is seen in the structural integrity of the adsorbent. As shown in Fig.1. (g to l), the nanoparticles are generated at a temperature of $400^{\circ} \mathrm{C}$ and are planar and progress to tabularization by increasing the pyrolysis temperature.
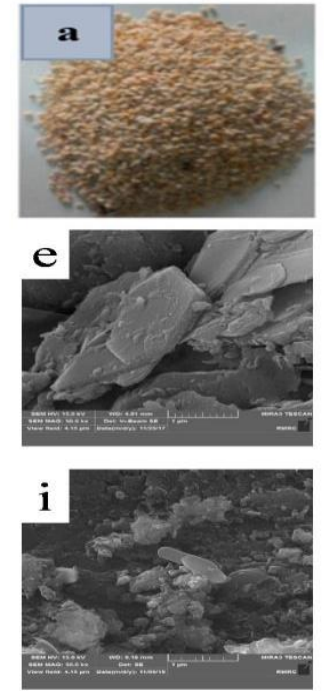
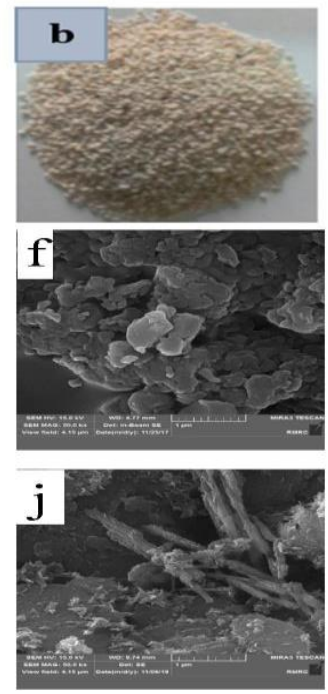
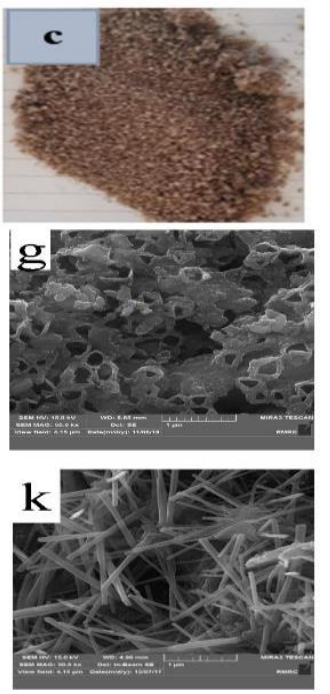
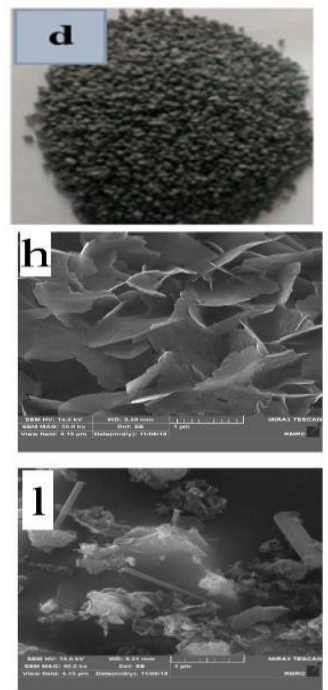

Fig. 1. Silica grains: (a) raw silica sand, (b) acid-washed silica sand,(c) Sand covered with waste Garbage leachate, and (d) silica-coated with Nanoparticles (NRs); SEM images: (e)acid washed silica, (f)Silica covered with waste Garbage leachate, SEM images of Nano absorbent at (g) $300{ }^{\circ} \mathrm{C}$, (h) $400{ }^{\circ} \mathrm{C}$, (i) $500{ }^{\circ} \mathrm{C}$, (j) $600{ }^{\circ} \mathrm{C}$, (k) $700{ }^{\circ} \mathrm{C}$, and (I) $800{ }^{\circ} \mathrm{C}$

In chemistry, for identifying molecules and studying intramolecular bonds and chemical bonding, Raman spectroscopy is employed. Given that vibrational frequencies are specific to the symmetry and chemical bonds of a molecule (the fingerprint region of organic molecules is in the 
500-1500 cm $\mathrm{cm}^{-1}$ wavenumber range) [36], Raman presents a fingerprint for identifying molecules. For example, IR and Raman spectra were utilized for determination of the vibrational frequencies of $\mathrm{Si}_{2} \mathrm{O}_{2}, \mathrm{Si}_{3} \mathrm{O}_{3}$, and $\mathrm{SiO}$ based on normal coordinate analyses [37]. In addition, Raman is spectroscopy employed for studying the addition of a substrate to an enzyme. In nanotechnology, a Raman microscope can be employed for the analysis of nanowires for a better understanding of their structures. The radial breathing mode of carbon nanotubes is usually utilized for evaluation of their diameter. The Raman test results are shown in Fig.2.a, where the sand is coated with garbage leachate. This figure shows different peaks, which can be attributed to the different elements available in the garbage leachate and their coverage at the sand surface. However, peaks demonstrate the formation of NRs on the sand surface at other parts.
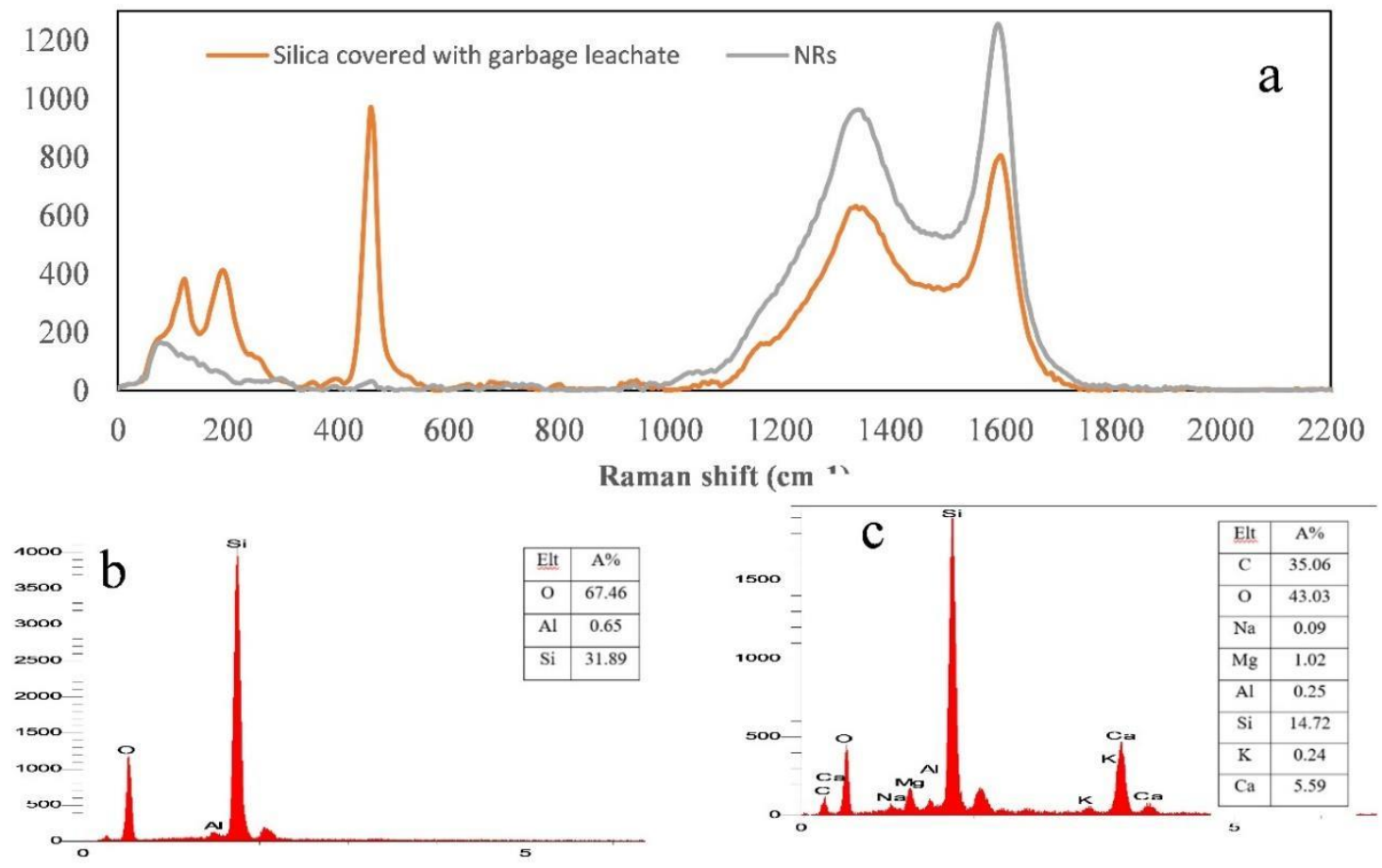

Fig. 2. (a)Raman test: Silica covered with garbage leachate and NRs $\left(700^{\circ} \mathrm{C}\right)$, EDS test: (b) acid-washed silica, (c) silica-coated with NRs. 
EDS is an analytical approach that is employed the sample's elemental analysis or chemical characterization. It is on the basis of the interaction of some X-ray excitation sources and a sample. Its characterization capacity is mainly because of the fact that the elements have a unique atomic structure, which provides a unique set of peaks on its electromagnetic emission spectrum [33] (that is the main principle of spectroscopy). Fig.2.b indicates the EDS analysis results for acid wash sand, which shows the presence of oxygen, silica, and a small amount of aluminum, Fig.2.c indicates the adsorbents prepared in this work. Several elements are coated on the sand surface because of the leaching of sand on the sand.

\subsection{Experiments of batch adsorption}

\subsubsection{Statistical analysis}

Using ANOVA, the quadratic model's adequacy is evaluated (Table 2). P-value and F-value determine insignificant and significant terms. The smaller $P$ value and the larger $F$ value suggest that the terms are more substantial terms [38], [39]. Hence, as observed in Table 2, A, B, C, AB, $A C$, and $B^{2}$, for Removal\% 4-NP were more important. In addition, based on Table 2, we have about $C e A, B, C, A B, A C, A^{2}$, and $B^{2}$ for Output Concentration of 4-NP were more important. In a similar way, the $p$-values of the model were smaller than 0.05 , so the model was significant statistically. Additionally, the high $\mathrm{R}^{2}$-values suggest a good agreement between the calculated and experimental data. Similarly, the difference between the predicted coefficient of determination (Pred. $R^{2}$ ) and the adjusted coefficient of determination (Adj. $R^{2}$ ) was below 0.2, which confirmed the model accuracy for 4-NP. Moreover, Adeq. Precision, specifying the signal to noise ratio, was above 4 , which indicates an adequate signal [40].

Table 2. ANOVA for Removal\% and Ce 4-NP

\begin{tabular}{|c|c|c|c|c|c|c|c|c|c|c|}
\hline \multirow[t]{2}{*}{ Source } & \multicolumn{2}{|c|}{$\begin{array}{l}\text { Sum of } \\
\text { Squares }\end{array}$} & \multicolumn{2}{|c|}{$\mathrm{df}$} & \multicolumn{2}{|c|}{$\begin{array}{l}\text { Mean } \\
\text { Square }\end{array}$} & \multicolumn{2}{|c|}{$\begin{array}{c}\mathrm{F} \\
\text { Value }\end{array}$} & \multicolumn{2}{|c|}{$\begin{array}{l}\text { p-value } \\
\text { Prob }>F\end{array}$} \\
\hline & $\mathrm{R} \%$ & $\mathrm{Ce}$ & R\% & $\mathrm{Ce}$ & $\mathrm{R} \%$ & $\mathrm{Ce}$ & $\mathrm{R} \%$ & $\mathrm{Ce}$ & $\mathrm{R} \%$ & $\mathrm{Ce}$ \\
\hline
\end{tabular}




\begin{tabular}{|c|c|c|c|c|c|c|c|c|c|c|c|}
\hline Model & $\begin{array}{r}6004.7 \\
6\end{array}$ & 2.61 & 6 & 7 & $\begin{array}{r}1000.7 \\
9\end{array}$ & 0.37 & 268.43 & 1096.18 & $<0.005$ & $<0.005$ & significant \\
\hline A: 4-NP & 223.51 & 1.47 & 1 & 1 & 223.51 & 1.47 & 59.95 & 4315.75 & $<0.005$ & $<0.005$ & \\
\hline B: Time & $\begin{array}{r}2402.6 \\
5\end{array}$ & 0.40 & 1 & 1 & $\begin{array}{r}2402.6 \\
5\end{array}$ & 0.40 & 644.42 & 1174.27 & $<0.005$ & $<0.005$ & \\
\hline C: adsorbent & $\begin{array}{r}2951.3 \\
1\end{array}$ & 0.25 & 1 & 1 & $\begin{array}{r}2951.3 \\
1\end{array}$ & 0.26 & 791.58 & 750.25 & $<0.005$ & $<0.005$ & \\
\hline$A B$ & 192.02 & 0.31 & 1 & 1 & 192.02 & 0.31 & 51.51 & 885.61 & $<0.005$ & $<0.005$ & \\
\hline$A C$ & 58.44 & 0.14 & 1 & 1 & 58.44 & 0.14 & 15.67 & 422.066 & $<0.005$ & $<0.005$ & \\
\hline$A^{2}$ & & 0.011 & & 1 & & 0.011 & & 31.62 & $<0.005$ & $<0.005$ & \\
\hline $\mathrm{B}^{2}$ & 173.84 & 0.005 & 1 & 1 & 173.84 & 0.005 & 46.63 & 15.90 & $<0.005$ & $<0.005$ & \\
\hline Residual & 44.74 & 0.0038 & 12 & 11 & 3.73 & 0.0003 & & & $<0.005$ & $<0.005$ & \\
\hline Lack of Fit & 37.92 & 0.0031 & 8 & 7 & 4.74 & $\begin{array}{c}0.0004 \\
4\end{array}$ & 2.77 & 2.56 & 0.17 & 0.190093 & $\begin{array}{l}\text { not } \\
\text { significant }\end{array}$ \\
\hline Pure Error & 6.83 & $<0.005$ & 4 & 4 & 1.71 & $<0.005$ & & & & & \\
\hline Cor Total & 6049.5 & 2.67 & 18 & 18 & & & & & & & \\
\hline Mean & 66.77 & 0.37 & & & & & & & & & \\
\hline Std. Dev. & 1.93 & 0.018 & & & & & & & & & \\
\hline $\mathrm{R}^{2}$ & 0.9926 & 0.9986 & & & & & & & & & \\
\hline Adj. $R^{2}$ & 0.9889 & 0.9977 & & & & & & & & & \\
\hline Pred. $\mathrm{R}^{2}$ & 0.979 & 0.9955 & & & & & & & & & \\
\hline C. V. \% & 2.89 & 5.05 & & & & & & & & & \\
\hline Model Precision & 63.83 & 124.94 & & & & & & & & & \\
\hline
\end{tabular}

Fig.3. ( $\mathbf{a}$ and $\mathbf{b}$ ) indicates plotting the predicted values of equilibrium concentration versus the actual values. As observed, the predicted points show approximately a linear behavior, and they have a good agreement with experimental data. Besides, the studentized residuals (Fig.3. c and d) have a normal distribution, which presents an approximately linear behavior that suggests satisfaction of the normality assumption. The interaction between the parameters and their concurrent impact on the response is studied by perturbation (Fig.4. $\mathbf{g}$ and $\mathbf{h}$ ) and 3D response surface graphs (Fig.4. e and f). Fig.4. $\mathbf{g}$ indicates that increasing the adsorbent dose and contact time reduces the equilibrium concentration of 4-NP. There are many adsorption sites at a high adsorbent dose. Besides, higher contact time could lead to higher 4-NP adsorption on the 
adsorbent surface. In addition, it is evident that decreasing 4-NP concentration reduces the amount of equilibrium concentration.
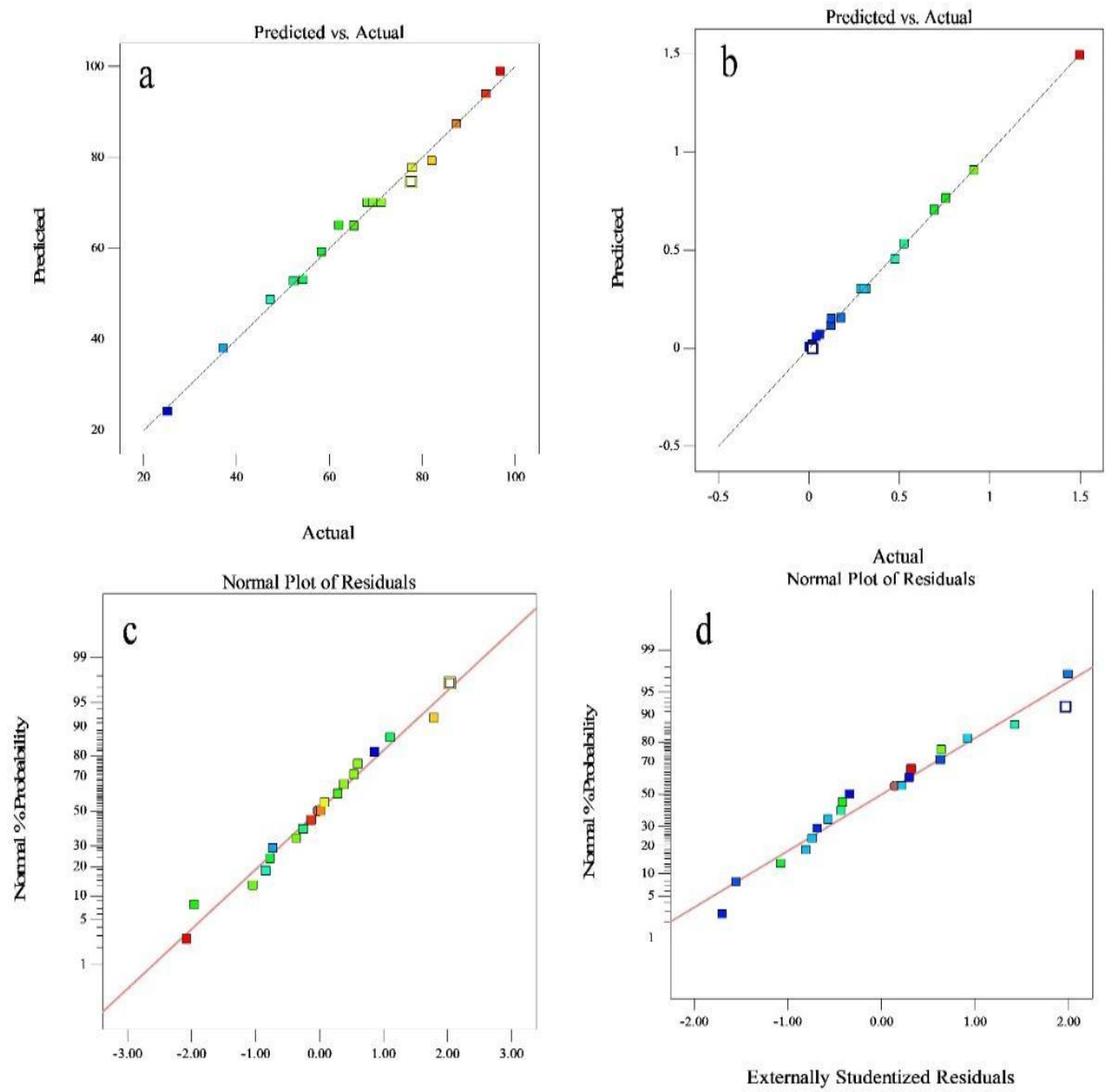

Externally Studentized Residuals

Fig.3. a, b Plot of predicted values versus actual values. c, $\mathbf{d}$ Normal probability plot of external studentized residuals for Removal\% 4-NP and Ce 4-NP 

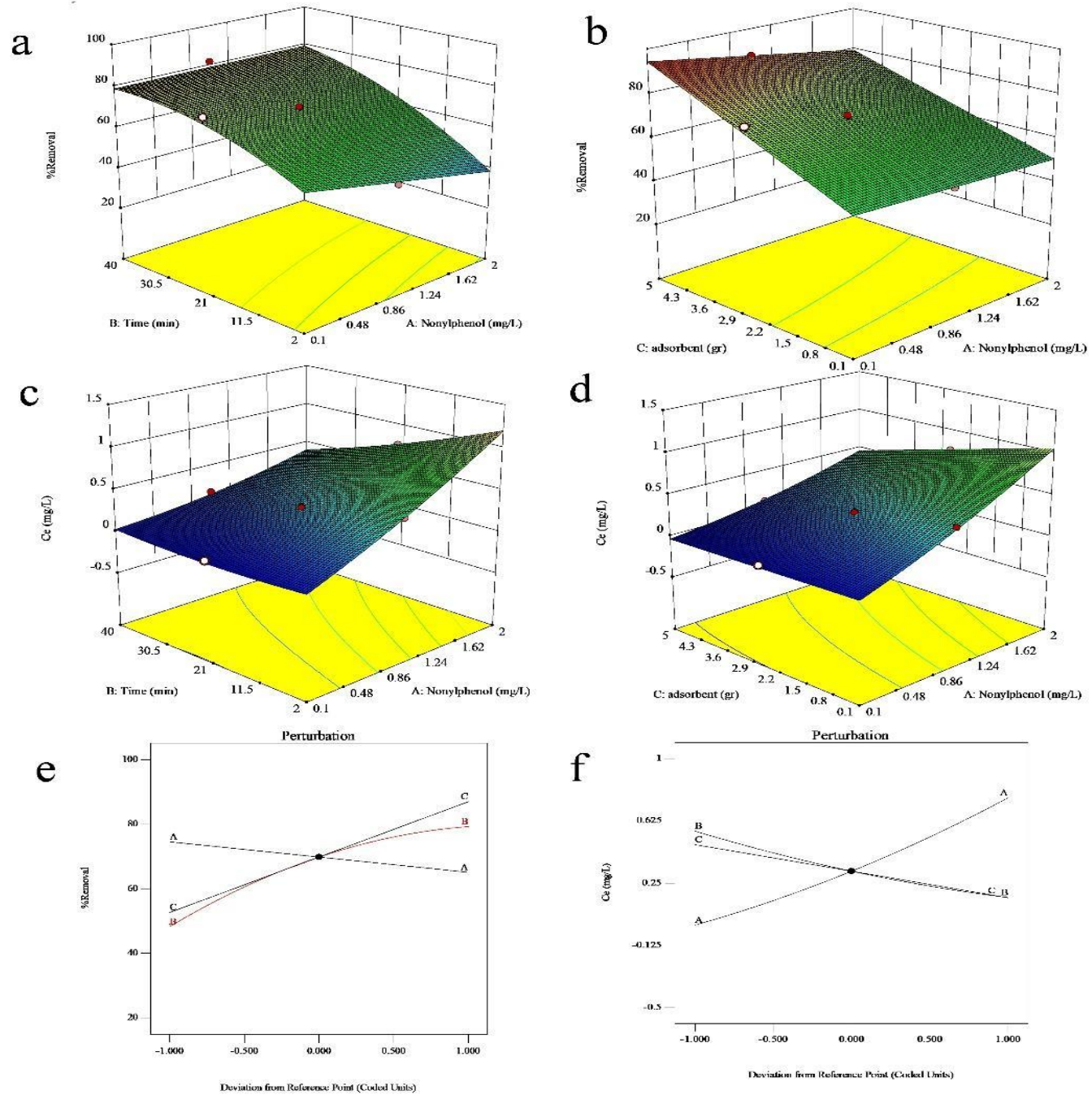

Fig.4. Respectively.3D response surface graphs of 4-NP for (a) interaction between Removal\% and time, (b) interaction between adsorbent and Removal\%, (c)interaction between time and $\mathrm{Ce}$, (d)interaction between time and $\mathrm{Ce}(\mathbf{e})$ Deviation from the reference point for $\mathrm{Re} \%$, (f) Deviation from the reference point for Ce.

\subsubsection{Comparative study and impact of initial concentration and contact time}

A comparative analysis was performed on the acid-washed silica, initial silica, and NRs coated silica for determining the removal capacity of 4-NP. The results of various experiments showed that none of the acid-washed silica grains and the initial silica grains are able to eliminate 4-NP. Following these tests, it was indicated that the proposed adsorbent is highly capable of removal 
of 4-NP. Then, we investigated the impact of contact time (2-40 min), initial 4-NP concentration (0.1-2 $\left.\mathrm{mg} \mathrm{L}^{-1}\right)$, and the amount of adsorbent (1-50 $\left.\mathrm{gr} \mathrm{L}^{-1}\right)$. According to Fig.5, the 4-NP adsorption onto NRs (qe) had a rapid phase firstly, pursued by a slow phase until the equilibrium is achieved. The initial quick phase is associated with the fast adsorption of 4-NP on adsorption sites available on NRs. By occupation of these sites, the adsorption rate reduces. Previous researches reported similar findings [27]. Based on this figure, the equilibrium time for NRs is reached at almost 2040 minutes. In addition, the adsorption rate increases by the increase in the initial 4-NP to a maximum of $2 \mathrm{mg} \mathrm{L}^{-1}$, which might be attributed to the increasing collisions of adsorbate molecules with the adsorbent material. Moreover, the diffusion driving force of 4-NP across external surface of nano absorbent increases presumably by increasing the initial concentration.

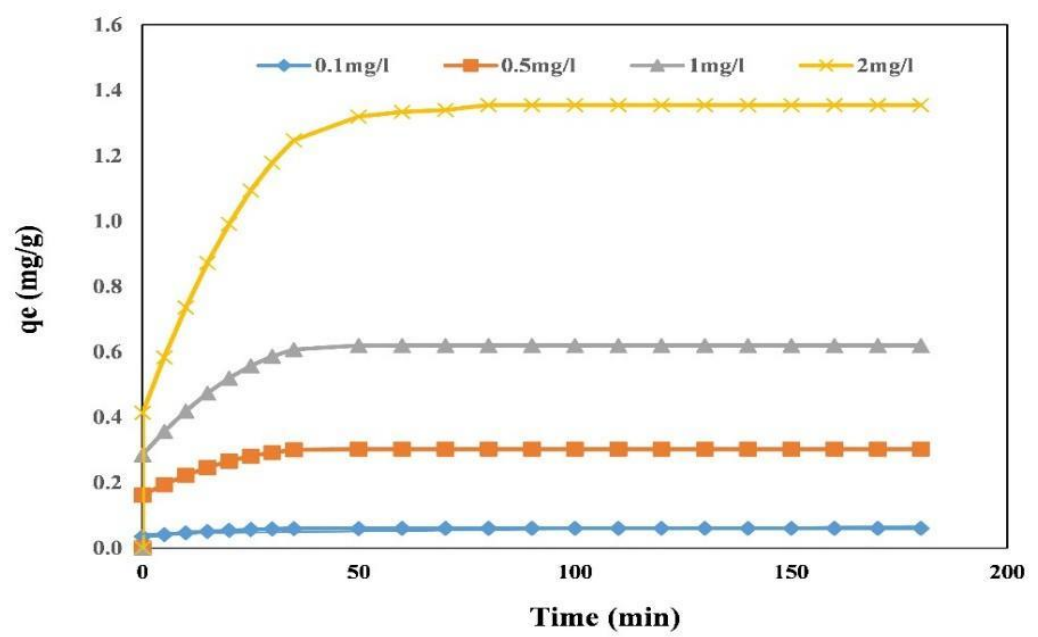

Fig.5. Adsorption time effect at varying concentrations of 4-NP.

\subsubsection{The results of the adsorption isotherms}

Table 3 gives the parameters and errors calculated by five isotherm models for 4-NP adsorption. Based on the error functions and $\mathrm{R}^{2}$ values, Langmuir isotherm and Redlich-Peterson model was the best one for explaining 4-NP adsorption process. As already noted, $\mathrm{R}_{\mathrm{L}}$ represents the adsorption nature. Regarding 4-NP, the $R_{L}$ was in $0.72-0.98$ range $\left(0<R_{L}<1\right)$, indicating optimal adsorption. 


\subsubsection{The results of the adsorption kinetics}

We used five kinetic models at three initial concentrations $\left(0.1,1,2 \mathrm{mg} \mathrm{L}^{-1}\right)$. For determining the accuracy of the models, we calculated two error functions (chi-square test $\left(\chi^{2}\right)$ and RMSE), the results of which are given in Table 4. All kinetics of the used models showed a good agreement, particularly at high pollutant concentrations. However, the intraparticle diffusion model and pseudo-second-order model indicated a large correlation coefficient and negligible amounts of error.

Table 4. Kinetic parameters of 4-NP

\begin{tabular}{llccc}
\hline & Parameters & \multicolumn{3}{c}{ Initial concentration $\left(\mathrm{mg} \mathrm{L}^{-1}\right)$} \\
& & 0.1 & 1 & 2 \\
\hline \multirow{2}{*}{ Pseudo-first-order } & $\mathrm{qe}_{\mathrm{e}}\left(\mathrm{mg} \mathrm{g}^{-1}\right)$ & 0.06 & 0.62 & 1.36 \\
$\log \left(\mathbf{q}_{\mathbf{e}}-\mathbf{q}_{\mathbf{i}}\right)=\log \left(\mathbf{q}_{\mathbf{e}}\right)-\frac{\mathbf{k}_{\mathbf{1}} \mathbf{t}}{2.303}$ & $\mathrm{R}^{2}$ & 0.978 & 0.982 & 0.985 \\
& $\chi^{2}$ & 0.083 & 0.443 & 0.911 \\
& $\mathrm{RMSE}$ & 0.021 & 0.186 & 0.356 \\
& $\mathrm{k}$ ( $: \mathrm{min}^{-1}$ & 0.105 & 0.088 & 0.068 \\
& $\mathrm{q}_{\mathrm{e}}(\mathrm{calc}): \mathrm{mg} \mathrm{g}^{-1}$ & 0.043 & 0.532 & 1.34
\end{tabular}

$\begin{array}{llccc}\text { Pseudo-second-order } & \mathrm{R}^{2} & 0.999 & 0.999 & 0.998 \\ \frac{\mathbf{t}}{\mathbf{q}_{\mathbf{i}}}=\frac{1}{\mathbf{k}_{2} \mathbf{q}_{\mathbf{e}}^{2}}+\left(\frac{1}{\mathbf{q}_{\mathbf{e}}}\right) \mathbf{t} & \mathrm{X}^{2} & 0.00002 & 0.0006 & 0.0022 \\ & \mathrm{RMSE} & 0.0004 & 0.0063 & 0.015 \\ & \mathrm{k}_{2}: \mathrm{g} \mathrm{mg}^{-1} \mathrm{~min}^{-1} & 3.504 & 0.158 & 0.036 \\ & \mathrm{q}_{\mathrm{e}}(\mathrm{calc}): \mathrm{mg} \mathrm{g}^{-1} & 0.066 & 0.749 & 1.78 \\ & & & & \\ & & & & \\ \text { Elovich } & \mathrm{R}^{2} & 0.979 & 0.997 & 0.996\end{array}$




\begin{tabular}{|c|c|c|c|c|}
\hline \multirow{4}{*}{$\mathbf{q}_{\mathbf{t}}=\frac{1}{\boldsymbol{\beta}} \ln (\boldsymbol{\alpha} \boldsymbol{\beta})+\frac{1}{\boldsymbol{\beta}} \ln (\mathbf{t})$} & $\chi^{2}$ & 0.0001 & 0.0002 & 0.001 \\
\hline & RMSE & 0.0007 & 0.0035 & 0.011 \\
\hline & $\alpha: \mathrm{g} \mathrm{mg}^{-1} \min ^{-1}$ & 0.12 & 0.24 & 0.23 \\
\hline & $\beta: g \mathrm{mg}^{-1}$ & 102.86 & 6.68 & 2.4 \\
\hline \multirow[t]{5}{*}{ Intraparticle Diffusion } & $\mathrm{R}^{2}$ & 0.945 & 0.986 & 0.996 \\
\hline & $x^{2}$ & 0.0001 & 0.0009 & 0.0008 \\
\hline & RMSE & 0.001 & 0.0082 & 0.0115 \\
\hline & $\mathrm{k}_{\mathrm{p}}: \mathrm{mg} \min ^{-1 / 2} \mathrm{~g}^{-1}$ & 0.004 & 0.065 & 0.18 \\
\hline & $\mathrm{C}: \mathrm{mg} \mathrm{g}^{-1}$ & 0.034 & 0.22 & 0.17 \\
\hline Liquid Film Diffusion & $\mathrm{R}^{2}$ & 0.984 & 0.982 & 0.992 \\
\hline \multirow[t]{3}{*}{$\operatorname{Ln}(1-\mathbf{F})=-k_{f d} t$} & $\chi^{2}$ & 0.0009 & 0.009 & 0.025 \\
\hline & RMSE & 0.002 & 0.026 & 0.059 \\
\hline & $K_{f d}: \min ^{-1}$ & 0.11 & 0.088 & 0.062 \\
\hline
\end{tabular}

Table 3. Isotherm parameters obtained by linear regression and error values for 4-NP adsorption on the adsorbent

\begin{tabular}{|c|c|c|c|c|c|c|}
\hline Isotherm & Equation & $\mathbf{R}^{2}$ & RMSE & $x^{2}$ & Parameter & Value \\
\hline \multirow[t]{2}{*}{ Freundlich } & $\ln q_{e}=\ln K_{F}+\frac{1}{n_{F}} \ln C_{e}$ & 0.9995 & 0.0183 & 0.0020 & $\mathrm{n}_{\mathrm{F}}$ & 1.055 \\
\hline & & & & & $\begin{array}{c}\mathrm{K}_{\mathrm{F}}: \mathrm{mg} \mathrm{g} \\
{ }^{1)}(\mathrm{L} . \mathrm{mg})^{1 / \mathrm{n}}\end{array}$ & 1.057 \\
\hline \multirow[t]{3}{*}{ Langmuir } & $\frac{C_{e}}{q_{e}}=\frac{1}{K_{L} q_{m}}+\frac{C_{e}}{q_{m}}$ & 0.9999 & $5.22 \times 10^{-5}$ & $2.11 \times 10^{-8}$ & $\mathrm{q}_{\mathrm{m}}: \mathrm{mgL}^{-1}$ & 6.447 \\
\hline & & & & & $\mathrm{K} \mathrm{L}: \mathrm{L} \mathrm{mg}^{-1}$ & 0.1887 \\
\hline & $R_{L}=\frac{1}{1+K_{L} \times C_{0}}$ & & & & $\mathrm{R}_{\mathrm{L}}$ & $0.72-0.98$ \\
\hline Radke-Prausnitz & $\frac{C_{e}}{q_{e}}=\frac{1}{K_{R P} q_{m}}+\frac{C_{e}^{m}}{q_{m}}$ & 0.9995 & 0.0039 & 0.0001 & $\mathrm{~m}$ & 0.0594 \\
\hline
\end{tabular}




\begin{tabular}{|c|c|c|c|c|c|c|}
\hline & & & & & $K_{R P}: L^{-1}$ & 51.9149 \\
\hline & & & & & $\mathrm{q}_{\mathrm{m}}: \mathrm{mg} \mathrm{g}^{-1}$ & 1.0860 \\
\hline \multirow[t]{4}{*}{ UT Isotherm } & $\ln \left(\frac{C_{e}}{C_{e}^{a d}}-\frac{K_{d}}{C_{m}}\right)=-b \ln C_{m}+b \ln C_{e}$ & 0.9808 & 0.0046 & 0.0001 & $\mathrm{q}_{\mathrm{m}}: \mathrm{mg} \mathrm{g}^{-1}$ & 1.4523 \\
\hline & & & & & $\mathrm{Kd}_{\mathrm{d}}: \mathrm{mg} \mathrm{L}$ & 0.0085 \\
\hline & & & & & b & 0.1012 \\
\hline & & & & & FCF & 0.0059 \\
\hline \multirow[t]{3}{*}{ Redlich-Peterson } & $\ln \left(K_{R} \frac{C_{e}}{q_{e}}-1\right)=g \ln C_{e}+\ln \alpha_{R}$ & 0.9809 & 0.0046 & 0.0001 & $\mathrm{~g}$ & 0.1018 \\
\hline & & & & & $K_{R}: L^{-1}$ & 84.5706 \\
\hline & & & & & $\alpha_{\mathrm{R}}:\left(\mathrm{L} \mathrm{mg}^{-1}\right)^{\mathrm{g}}$ & 80.9357 \\
\hline \multirow[t]{3}{*}{ Dubinin- } & $\ln q_{e}=\ln q_{s}-\beta \varepsilon^{2}$ & 0.9805 & 0.0403 & 0.0109 & $\mathrm{q}_{\mathrm{s}}: \mathrm{mg} \mathrm{g}^{-1}$ & 1.3158 \\
\hline & $\varepsilon=R T \ln \left(1+\frac{1}{C_{e}}\right)$ & & & & $\beta: \mathrm{mol}^{2} \mathrm{~J}^{-2}$ & $1.0968 \times 10^{-7}$ \\
\hline & $E=\frac{1}{\sqrt{2 \beta}}$ & & & & $\mathrm{E}: \mathrm{kJ} \mathrm{mol}^{-1}$ & 2135.0715 \\
\hline
\end{tabular}

\subsubsection{The results of the adsorption thermodynamic}

We investigated five different temperatures $\left(283,293,303,313,323^{\circ} \mathrm{k}\right)$ in this study for obtaining thermodynamic parameters. The negative values of $\Delta \mathrm{G}^{\circ}$ represent the adsorption process as a spontaneous and practical process. Furthermore, increasing the temperature decreased $\Delta G^{\circ}$, which shows that high temperature would provide better states for 4-NP adsorption on NRs. In fact, it indicates the favorability of high temperature. In addition, positive $\Delta \mathrm{H}\left(31.53 \mathrm{~kJ} \mathrm{~mol}^{-1}\right)$ value shows that 4 -NP on NRs has a thermal nature, also revealing that $\Delta \mathrm{S}^{\circ}$ 
(122.37 $\mathrm{J} \mathrm{mol}^{-1} \mathrm{~K}^{-1}$ ) is positive. It indicates increasing the random degree at the liquid-solid interface (Fig.6).

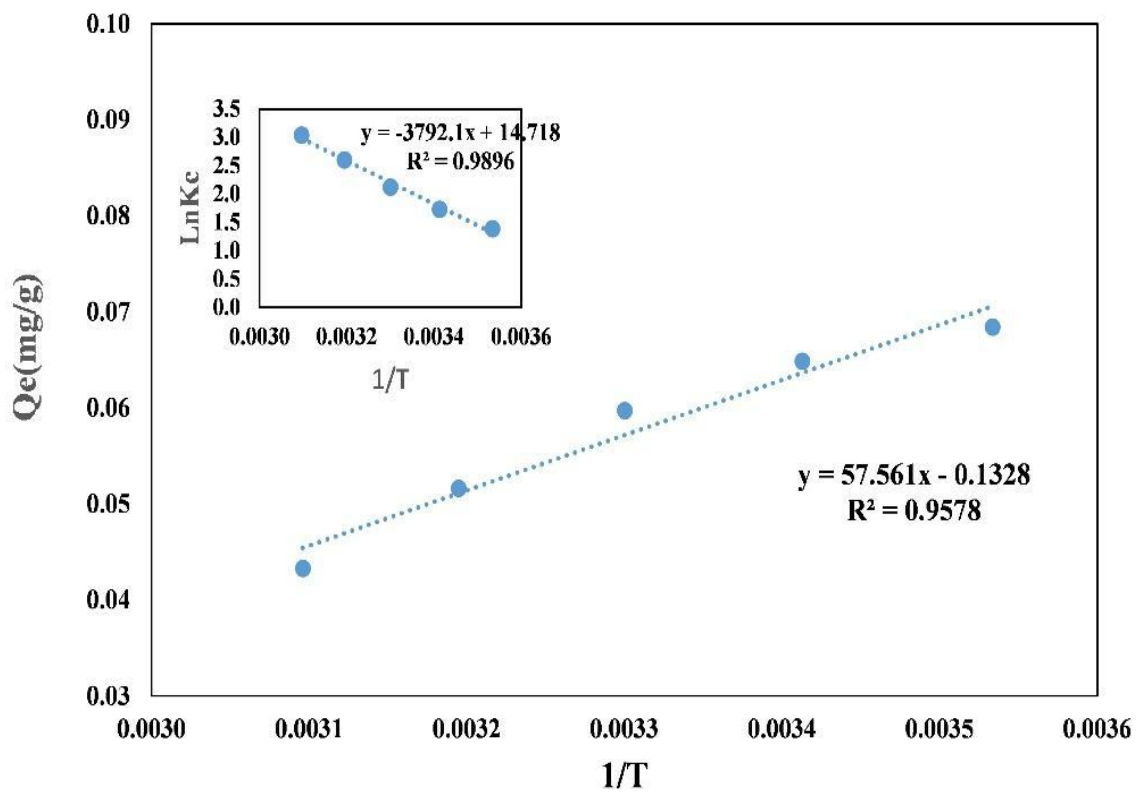

Fig.6. The thermodynamic plot for adsorption of 4-NP using NRs

\subsection{New adsorbent regeneration}

Because of the expensiveness of Nano absorbent, the 4-NP desorption from the NRs surface is a crucial phase. After seven reiterations of this procedure, the removal efficiency varied from $80 \%$ to $41 \%$, which is shown in Fig.7. Reduction of adsorption following regeneration can be attributed to incomplete 4-NP desorption from the NRs surface.

According to the previous studies [43], "the unit cost of Nano absorbent is expected to be further decreased in the future. Thus, nano absorbents could become cost-effective sorbents. Hence, it is highly recommended to perform more researches on the elimination of other environmental pollutants using Nano absorbent." 


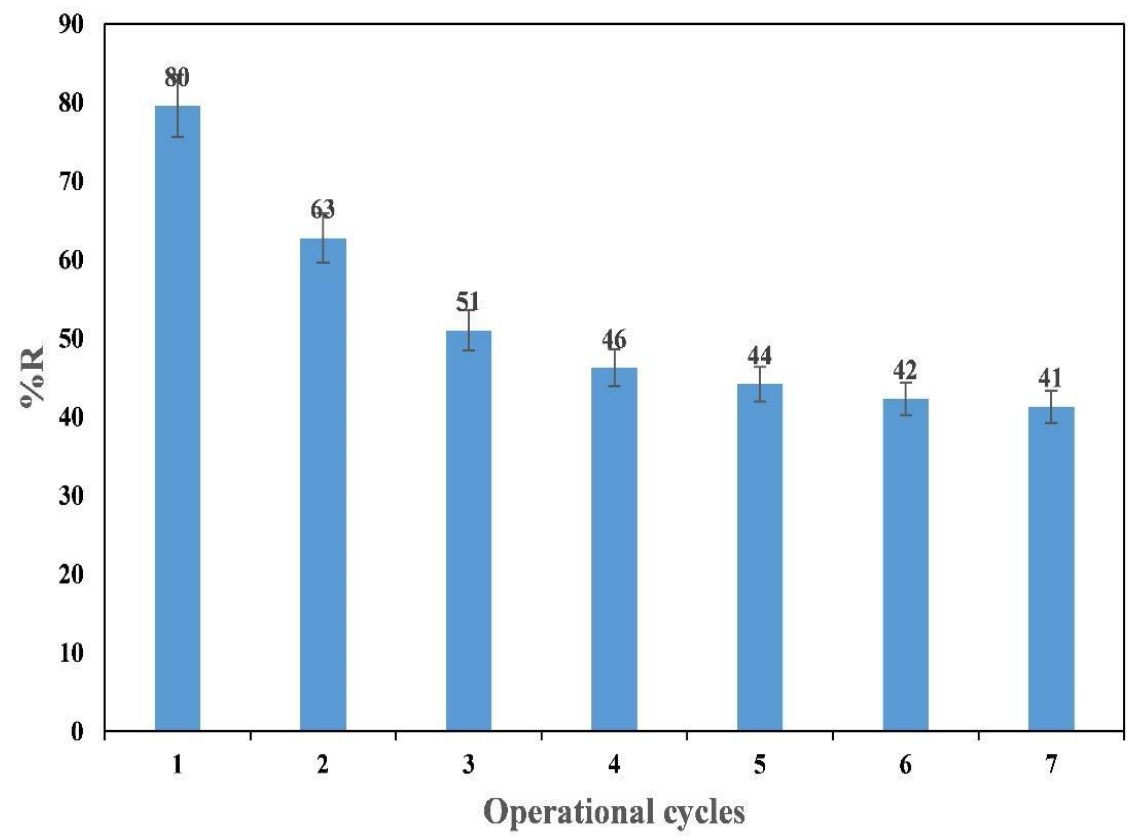

Fig. 7. Regeneration and removal efficiency of 4-NP adsorption.

\section{Conclusions}

We generated a newly engineered adsorbent in this work by covering silica grains with Engineering nano absorbent prepared from waste Garbage leachate. NRs showed efficiency and practicality as the adsorbent for 4-NP removal from aquatic environments. There was such a strong chemical bonding between sand particles and NRs that NRs stayed on the surface of sand particles the following ultrasonication. Significant quadratic equations were gained by central composite design (CCD) for 4-NP. The contact time, initial concentrations of adsorbate, and adsorbent loading were the parameters that significantly affected the response. Different isotherms, i.e., Freundlich, Langmuir, Redlich-Peterson, UT, and Radke-Prausnitz, were studied in equilibrium studies. According to the results, the adsorption process showed the best fit with Redlich-Peterson and Langmuir isotherm. In addition, Kinetic studies were performed using such models as Pseudo-second-order, Pseudo-first-order, Elovich, and Intraparticle Diffusion. Based on the results of experiments, Intraparticle and Pseudo-second-order models were best fitted with experimental data. Moreover, the adsorption is an endothermic, optimal, spontaneous, and 
disorderly process at the liquid-solid interface. According to these experiments, the new adsorbent is highly capable of removing 4-NP with a simple regeneration process.

\section{Abbreviations}

MPs : Micro pollutants

4-OP : 4-Octylphenol

BPA : Bisphenol A

4-NP : 4-Nonylphenol

NP : Nonylphenol

NOM : Natural organic material

NRs : Carbon nanorods

UT : $\quad$ University of Tehran

\section{Acknowledgments}

Thanks to the Nanotechnology Lab of the Faculty of Environment, University of Tehran, who provided much support for this research.

\section{References}

[1] R. L. Zornitta, K. M. Barcelos, F. G. E. Nogueira, and L. A. M. Ruotolo, "Understanding the mechanism of carbonization and $\mathrm{KOH}$ activation of polyaniline leading to enhanced electrosorption performance," Carbon N. Y., vol. 156, pp. 346-358, 2020.

[2] A. Priac et al., "Alkylphenol and alkylphenol polyethoxylates in water and wastewater: A review of options for their elimination," Arab. J. Chem., vol. 10, pp. S3749-S3773, 2017.

[3] E. Mosadegh, K. Ashrafi, M. S. Motlagh, and I. Babaeian, "Modeling the Regional Effects of Climate Change on Future Urban Ozone Air Quality in Tehran, Iran," ArXiv210904644 Phys., Sep. 2021, Accessed: Sep. 20, 2021. [Online]. Available: http://arxiv.org/abs/2109.04644

[4] E. Mosadegh, "Modeling the Regional Effects of Climate Change on Future Urban Air Quality (With Special Reference to Future Ozone Concentrations in Tehran, Iran)," M.S. thesis, School of Env., Univ. of Tehran, Tehran, Iran, Sep. 2013. DOI: $\underline{10.13140 / R G .2 .2 .23815 .32165}$ 
[5] Y. Luo et al., "A review on the occurrence of micropollutants in the aquatic environment and their fate and removal during wastewater treatment," Sci. Total Environ., vol. 473-474, pp. 619-641, 2014.

[6] IPCC, 2021: Summary for Policymakers. In: Climate Change 2021: The Physical Science Basis. Contribution of Working Group I to the Sixth Assessment Report of the Intergovernmental Panel on Climate Change [Masson-Delmotte, V., P. Zhai, A. Pirani, S. L. Connors, C. Péan, S. Berger, N. Caud, Y. Chen, L. Goldfarb, M. I. Gomis, M. Huang, K. Leitzell, E. Lonnoy, J.B.R. Matthews, T. K. Maycock, T. Waterfield, O. Yelekçi, R. Yu and B. Zhou (eds.)]. Cambridge University Press. In Press.

[7] E. Mosadegh and A. W. Nolin, "Estimating Arctic sea ice surface roughness by using back propagation neural network," vol. 2020, pp. C014-0005, Dec. 2020, Accessed: Sep. 05, 2021. [Online]. Available: https://ui.adsabs.harvard.edu/abs/2020AGUFMC014.0005M

[8] E. Mosadegh, I. Babaeian, and M. Baygi, Uncertainty Assessment of GCM Models in Predicting Temperature, Precipitation and Solar Radiation Under Climate Change Impact in Tehran, Iran. 2013.

[9] E. Mosadegh and I. Babaeian, "Uncertainty Analysis Of Future Projections Of Temperature, Precipitation, And Solar Radiation Under Global Warming Effect In Tehran, Iran," ArXiv210904622 Phys., Sep. 2021, Accessed: Sep. 20, 2021. [Online]. Available: http://arxiv.org/abs/2109.04622

[10] E. Mosadegh and I. Babaeian, "Projection Of Temperature And Precipitation For 2020-2100 For Tehran Region Using Post-processing Of General Circulation Models Output And Artificial Neural Network Approach," ArXiv210904619 Phys., Sep. 2021, Accessed: Sep. 20, 2021. [Online]. Available: http://arxiv.org/abs/2109.04619

[11] V. Geissen et al., "Emerging pollutants in the environment: A challenge for water resource management," Int. Soil Water Conserv. Res., vol. 3, no. 1, pp. 57-65, 2015.

[12] T. J. Bandosz, A. Policicchio, M. Florent, W. Li, P. S. Poon, and J. Matos, "Solar light-driven photocatalytic degradation of phenol on S-doped nanoporous carbons: The role of functional groups in governing activity and selectivity," Carbon N. Y., vol. 156, pp. 10-23, 2020.

[13] J. Mejia, E. Wilcox, S. Rayne, and E. Mosadegh, "Final report: Vehicle Miles Traveled Review", Desert Research Institute, Division of Atmospheric Sciences, Reno, Nevada, United States, Mar., 2019. DOI: 10.13140/RG.2.2.29814.52807. [Online]. Available: https://246902d0-612543ca-8e73-f2d67ba3ff27.filesusr.com/ugd/c115bf_4b5eeaa4a5ed4aa189989c4dadb9cfd9.pdf 
[14] E. Mosadegh, J. Mejia, E. M. Wilcox, and S. Rayne, "Vehicle Miles Travel (VMT) trends over Lake Tahoe area and its effect on Nitrogen Deposition," vol. 2018, pp. A23M-3068, Dec. 2018, Accessed: Sep. $2021 . \quad$ 05, Anline]. Available: https://ui.adsabs.harvard.edu/abs/2018AGUFM.A23M3068M

[15] J. Matos et al., "C-doped anatase TiO 2 : Adsorption kinetics and photocatalytic degradation of methylene blue and phenol, and correlations with DFT estimations," J. Colloid Interface Sci., vol. 547, pp. 14-29, 2019.

[16] X. T. Bui, T. P. T. Vo, H. H. Ngo, W. S. Guo, and T. T. Nguyen, "Multicriteria assessment of advanced treatment technologies for micropollutants removal at large-scale applications," Sci. Total Environ., vol. 563-564, pp. 1050-1067, 2016.

[17] Q. Zhou, M. Lei, J. Li, K. Zhao, and Y. Liu, "Sensitive determination of bisphenol A, 4-nonylphenol and 4-octylphenol by magnetic solid phase extraction with Fe@MgAl-LDH magnetic nanoparticles from environmental water samples," Sep. Purif. Technol., vol. 182, pp. 78-86, 2017.

[18] W. S. Zhou, B. Zhao, X. H. Huang, and X. Di Yang, "Electrochemical determination of 4nonylphenol on graphene-chitosan modified glassy carbon electrode," Fenxi Huaxue/ Chinese J. Anal. Chem., vol. 41, no. 5, pp. 675-680, 2013.

[19] EPA, “Aquatic life ambient water quality criteria - nonylphenol," Epa-822-R-05-005. p. 96, 2005.

[20] Z. Jin, X. Wang, Y. Sun, Y. Ai, and X. Wang, "Adsorption of 4-n-Nonylphenol and Bisphenol-A on Magnetic Reduced Graphene Oxides: A Combined Experimental and Theoretical Studies," Environ. Sci. \&amp; Technol., vol. 49, no. 15, pp. 9168-9175, Jul. 2015.

[21] Z. Yang et al., "Removal of trace nonylphenol from water in the coexistence of suspended inorganic particles and NOMs by using a cellulose-based flocculant," Chemosphere, vol. 161, pp. 482-490, 2016.

[22] A. F. Toro-Vélez et al., "BPA and NP removal from municipal wastewater by tropical horizontal subsurface constructed wetlands," Sci. Total Environ., vol. 542, pp. 93-101, Jan. 2016.

[23] L. F. Ren, R. Chen, X. Zhang, J. Shao, and Y. He, "Phenol biodegradation and microbial community dynamics in extractive membrane bioreactor (EMBR) for phenol-laden saline wastewater," Bioresour. Technol., vol. 244, no. July, pp. 1121-1128, 2017.

[24] H. A. Asmaly, B. Abussaud, Ihsanullah, T. A. Saleh, V. K. Gupta, and M. A. Atieh, "Ferric oxide nanoparticles decorated carbon nanotubes and carbon nanofibers: From synthesis to enhanced removal of phenol," J. Saudi Chem. Soc., vol. 19, no. 5, pp. 511-520, 2015. 
[25] D. Koeppenkastrop and E. H. De Carlo, "Uptake of rare earth elements from solution by metal oxides," Environ. Sci. \&amp; Technol., vol. 27, no. 9, pp. 1796-1802, May 2002.

[26] S. Yean et al., "Effect of magnetite particle size on adsorption and desorption of arsenite and arsenate," J. Mater. Res., vol. 20, no. 12, pp. 3255-3264, 2005.

[27] Q. Li et al., "Antimicrobial nanomaterials for water disinfection and microbial control: Potential applications and implications," Water Res., vol. 42, no. 18, pp. 4591-4602, 2008.

[28] A. Nabavi-Pelesaraei, R. Bayat, H. Hosseinzadeh-Bandbafha, H. Afrasyabi, and K. wing Chau, "Modeling of energy consumption and environmental life cycle assessment for incineration and landfill systems of municipal solid waste management - A case study in Tehran Metropolis of Iran," J. Clean. Prod., vol. 148, pp. 427-440, 2017.

[29] S. Q. Aziz, H. A. Aziz, M. S. Yusoff, M. J. K. Bashir, and M. Umar, "Leachate characterization in semi-aerobic and anaerobic sanitary landfills: A comparative study," J. Environ. Manage., vol. 91, no. 12, pp. 2608-2614, 2010.

[30] G. Przydatek and W. Kanownik, "Impact of small municipal solid waste landfill on groundwater quality," Environ. Monit. Assess., vol. 191, no. 3, pp. 1-14, 2019.

[31] M. Regadío et al., "Pollution profiles and physicochemical parameters in old uncontrolled landfills," Waste Manag., vol. 32, no. 3, pp. 482-497, 2012.

[32] O. Article, "of Environmental Health and Sustainable Development Evaluation the Effect of Landfill Leachate on the Surface Water Quality : A Case Study in Tonekabon Landfill."

[33] J. Goldstein and E. All, Scanning Electron Microscopy and X-Ray Microanalysis. Bethlehem PA USA, 2003.

[34] Y. S. Lim and J. H. Kim, "Isotherm, kinetic and thermodynamic studies on the adsorption of 13dehydroxybaccatin III from Taxus chinensis onto Sylopute," J. Chem. Thermodyn., vol. 115, pp. 261-268, 2017.

[35] B. Sadhukhan, N. K. Mondal, and S. Chattoraj, "Optimisation using central composite design (CCD) and the desirability function for sorption of methylene blue from aqueous solution onto Lemna major," Karbala Int. J. Mod. Sci., vol. 2, no. 3, pp. 145-155, 2016.

[36] L. A. University of California, "The basics of Reading Infrared Spectrometry Graphs."

[37] R. . Khanna, "Raman-spectroscopy of oligomeric SiO species isolated in solid methane," Chem. Phys., vol. 111, no. 17, pp. 7887-7887, 1999.

[38] H. Kalavathy M., I. Regupathi, M. G. Pillai, and L. R. Miranda, "Modelling, analysis and optimization of adsorption parameters for H3PO4 activated rubber wood sawdust using 
response surface methodology (RSM)," Colloids Surfaces B Biointerfaces, vol. 70, no. 1, pp. 3545, 2009.

[39] M. Amini et al., "Application of response surface methodology for optimization of lead biosorption in an aqueous solution by Aspergillus niger," J. Hazard. Mater., vol. 154, no. 1-3, pp. 694-702, 2008.

[40] M. O. Saeed, K. Azizli, M. H. Isa, and M. J. K. Bashir, "Application of CCD in RSM to obtain optimize treatment of POME using Fenton oxidation process," J. Water Process Eng., vol. 8, pp. e7-e16, 2015.

[41] M. Baghdadi, "UT (University of Tehran) isotherm as a novel and useful adsorption isotherm for investigation of adsorptive removal of pollutants," J. Environ. Chem. Eng., vol. 5, no. 2, pp. 1906-1919, 2017.

[42] Y. Wang, P. Zhang, C. Fang Liu, L. Zhan, Y. Fang Li, and C. Z. Huang, "Green and easy synthesis of biocompatible graphene for use as an anticoagulant," RSC Adv., vol. 2, no. 6, pp. 2322-2328, 2012.

[43] G. Zhao, J. Li, and X. Wang, "Kinetic and thermodynamic study of 1-naphthol adsorption from aqueous solution to sulfonated graphene nanosheets," Chem. Eng. J., 2011.

[44] X. Yang, J. Li, T. Wen, X. Ren, Y. Huang, and X. Wang, "Adsorption of naphthalene and its derivatives on magnetic graphene composites and the mechanism investigation," Colloids Surfaces A Physicochem. Eng. Asp., vol. 422, pp. 118-125, 2013.

[45] E. Nariyan, A. Aghababaei, and M. Sillanpää, "Removal of pharmaceutical from water with an electrocoagulation process; effect of various parameters and studies of isotherm and kinetic," Sep. Purif. Technol., vol. 188, pp. 266-281, 2017.

[46] D. Balarak, F. Mostafapour, H. Azarpira, and A. Joghataei, "Langmuir, Freundlich, Temkin and Dubinin-radushkevich Isotherms Studies of Equilibrium Sorption of Ampicilin unto Montmorillonite Nanoparticles," J. Pharm. Res. Int., vol. 20, no. 2, pp. 1-9, 2017.

[47] S. A. Chaudhry, Z. Zaidi, and S. I. Siddiqui, "Isotherm, kinetic and thermodynamics of arsenic adsorption onto Iron-Zirconium Binary Oxide-Coated Sand (IZBOCS): Modelling and process optimization," J. Mol. Liq., vol. 229, pp. 230-240, 2017.

[48] K. Y. Foo and B. H. Hameed, "Insights into the modeling of adsorption isotherm systems," Chem. Eng. J., vol. 156, no. 1, pp. 2-10, 2010. 